\title{
Accumulation of Amino Acids by Saccharomyces cerevisiae Y185 with Phospholipids Enriched in Different Fatty-acyl Residues: a Statistical Analysis of Data
}

\author{
By JILL CALDERBANK,' MICHAEL H. J. KEENAN,'† \\ ANTHONY H. ROSE ${ }^{1 *}$ AND GEOFFREY D. HOLMAN ${ }^{2}$ \\ 'Zymology Laboratory and 'Biochemistry Group. School of Biological Sciences. \\ University of Bath, Bath BA2 7AY, Avon, UK
}

(Received 29 February 1984; revised 26 June 1984)

\begin{abstract}
Saccharomyces cerevisiae Y185, grown anaerobically in media containing ergosterol and palmitoleic, oleic or linoleic acids, synthesized phospholipids extensively enriched in the exogenously supplied fatty acid. A study was made of the effect of solute concentration on rates of accumulation of nine amino acids by organisms enriched in different fatty-acyl residues. Data were fitted using computer-aided statistical analysis to three equations to derive kinetic constants for accumulation. Analysis of data for two of the amino acids, namely L-threonine and L-histidine, showed different kinetics in organisms enriched in different fatty-acyl residues. Woolf-Hofstee plots for accumulation of L-threonine, as well as L-serine, showed abrupt changes in curvature at low concentrations with differently enriched organisms. Data for accumulation of both amino acids gave a significant fit to the model describing accumulation by one transport system without diffusion. Data for accumulation of L-histidine as well as Laspartic acid best fitted a model describing accumulation by one transport system and diffusion. Values for $K_{\mathrm{T}}$ and the diffusion constant, but not $V_{\max }$, differed only for accumulation of L-histidine in organisms with different fatty-acyl enrichments. A third model, describing accumulation by two separable transport systems, best fitted data for accumulation of Lglutamic acid and L-methionine. Data for accumulation of L-leucine, L-isoleucine and L-valine could not be fitted to any of the models. Woolf-Hofstee plots for accumulation of L-leucine and $\mathrm{L}$-isoleucine by organisms enriched in oleyl or linoleyl residues were superimposable, although similar plots for accumulation of L-valine differed in shape.
\end{abstract}

\section{INTRODUCTION}

When grown in media containing a poor nitrogen source such as proline, Saccharomyces cerevisiae synthesizes a general amino-acid permease (GAP), a high-velocity system which is particularly effective in transporting $D$ and $L$ isomers of basic and neutral amino acids (Grenson et al., 1970; Rytka, 1975). In such media, $S$. cerevisiae also synthesizes at least 10 other amino acid-transporting systems each of which is specific for just one or a small number of L-amino acids (Eddy, 1982; Gregory et al., 1982). When the yeast is grown in media containing a good nitrogen source such as ammonium ions, the GAP is not synthesized (Grenson et al., 1970; Grenson \& Hou, 1972), although specific amino acid-transporting systems continue to be elaborated.

Little is known of the manner in which plasma-membrane phospholipid and sterol composition affects the activity of solute-transport mechanisms in $S$. cerevisiae. By exploiting the anaerobically induced requirement in $S$. cerevisiae for a sterol and an unsaturated fatty acid (Andreasen \& Stier, 1953, 1954), both of which requirements are fairly broad (Light et al., 1962;

† Present address: AFRC Food Research Institute, Colney Lane Norwich, UK. 
Proudlock et al., 1968), Keenan \& Rose (1979) showed that $K_{\mathrm{T}}$ and $V_{\max }$ values for accumulation of L-arginine in S. cerevisiae NCYC 366, by both high- and low-affinity specific systems, differed in organisms enriched in oleyl as compared with linoleyl residues. Keenan et al. (1982), using the same technique, reported differences in $K_{\mathrm{T}}$ and $V_{\max }$ values for accumulation of Llysine by specific systems in organisms enriched in each of these fatty-acyl residues. These workers also described differences in the kinetic values for accumulation of L-asparagine in organisms enriched in palmitoleyl compared with oleyl residues.

The present paper extends this study on the effect of fatty-acyl unsaturation in plasmamembrane phospholipids in $S$. cerevisiae to accumulation by specific systems of nine other $L$-amino acids. In organisms lacking the GAP, five of these amino acids, namely $L$-aspartic and L-glutamic acids (Joiris \& Grenson, 1969; Darte \& Grenson, 1975; Cockburn et al., 1975), L-histidine (Grenson et al., 1968; Crabeel \& Grenson, 1970), L-methionine (Maw, 1963; Gits \& Grenson, 1967) and L-threonine (Gits \& Grenson, 1967; Gregory et al., 1982) are accumulated by systems some of which are shared with one or more other amino acids. Very little has been reported on accumulation of L-serine by $S$. cerevisiae, although Gits $\&$ Grenson (1967) on the basis of scanty evidence suggested that this amino acid and L-threonine are accumulated by the low-affinity L-methionine system. The remaining three amino acids, namely L-leucine, Lisoleucine and L-valine, are generally assumed to be accumulated by the same mechanism (Bussey \& Umbarger, 1970a, b; Ramos et al., 1975, 1977, 1980).

\section{METHODS}

Experimental cultures. Saccharomyces cerevisiae Y185, a haploid strain, was maintained on slopes of malt extract/yeast extract/glucose/peptone/agar medium (Wickerham, 1951). The yeast was grown anaerobically in a medium (pH 4.5) containing $\left(1^{-1}\right)$ : glucose $50 \mathrm{~g}$. $\left(\mathrm{NH}_{4}\right)_{2} \mathrm{SO}_{4} 3 \mathrm{~g}, \mathrm{KH}_{2} \mathrm{PO}_{4} 4.5 \mathrm{~g}$. yeast extract (Lab m; London Analytical \& Bacteriological Media, London, UK) $1.0 \mathrm{~g}, \mathrm{MgSO}_{4} .7 \mathrm{H}_{2} \mathrm{O} 250 \mathrm{mg}, \mathrm{CaCl}_{2} .2 \mathrm{H}_{2} \mathrm{O} 250 \mathrm{mg}$, ergosterol $5 \mathrm{mg}$, and $30 \mathrm{mg}$ of an unsaturated fatty acid, as indicated in the text. Cultures were inoculated and incubated anaerobically as described by Alterthum \& Rose (1973) and Keenan et al. (1982). Growth was followed by measuring optical density at $600 \mathrm{~nm}$, and organisms were harvested from late exponential-phase cultures (0.29$\left.0.31 \mathrm{mg} \mathrm{dry} \mathrm{wt} \mathrm{ml}^{-1}\right)$ by filtration through a membrane filter $(0.45 \mu \mathrm{m}$ pore size, $47 \mathrm{~mm}$ diam; Oxoid). Control cultures lacking ergosterol and an unsaturated fatty acid were incubated with each batch of experimental cultures and, when growth in the control exceeded $0.05 \mathrm{mg}^{\mathrm{dry}}$ wt $\mathrm{ml}^{-1}$, experimental cultures were discarded.

Measurement of velocity of amino-acid accumulation. Organisms which were to be used to measure the velocity of amino-acid accumulation were washed twice with PIPES/HCl buffer $(10 \mathrm{~mm})$ or citrate/trisodium citrate buffer

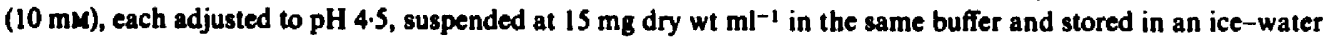
mixture. During storage, the suspension was stirred and the headspace in the storage vessel flushed with oxygenfree nitrogen gas. The suspension $(15 \mathrm{ml})$ used to measure the velocity of amino-acid accumulation consisted of PIPES or citrate buffer ( $\mathrm{pH} 4.5$ ) containing $100 \mathrm{~mm}$-glucose, $1 \mathrm{~mm}-\left(\mathrm{NH}_{4}\right)_{2} \mathrm{SO}_{4}, 0.5 \mathrm{mg}$ dry wt organisms $\mathrm{ml}^{-1}$ and an amino acid in the concentration range $10^{-6}$ to $10^{-1} \mathrm{M}$, including both radioactive and non-radioactive compounds. The specific activities of radioactive amino acids $\left(\mu \mathrm{Ci} \mu \mathrm{mol}^{-1} ; 1 \mu \mathrm{Ci}=37 \mathrm{kBq}\right)$ in the buffered

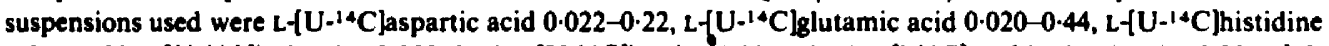

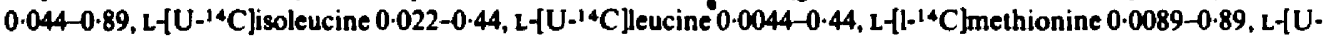
${ }^{14} \mathrm{C}$ serine $0.044-0.89$, L-[U-14 $\mathrm{C}$ threonine $0.056-4.44$, and $\mathrm{L}-\left[\mathrm{U}-{ }^{14} \mathrm{C}\right] \mathrm{valine} 0.022-0.44$. Ranges of specific activity are quoted since the tracer :carrier ratio was varied because of wide differences in the velocity of accumulation at different amino-acid concentrations. The suspension was contained in a round-bottomed Quickfit flask $(100 \mathrm{ml}$ capacity) fitted with a glass stoppered sampling port. During preparation of the suspension, the flask was maintained in a water bath at $30^{\circ} \mathrm{C}$. Its contents were stirred magnetically, and the inside of the flask continuously flushed with oxygen-free nitrogen gas. The experiment was started by adding amino acid (tracer and carrier) to the flask, after which portions $(1 \mathrm{ml})$ were removed at predetermined times, rapidly filtered through membrane filters $(0.45 \mu \mathrm{m}$ pore size, $25 \mathrm{~mm}$ diam; Millipore), and the filter and cells immediately washed with ice-cold PIPES or citrate buffer $(10 \mathrm{ml} ; \mathrm{pH} \mathrm{4.5)}$ containing the amino acid at the concentration included in the cell suspension. Filters were then transferred to scintillation vials containing $4 \mathrm{ml}$ of either Unisolve liquid scintillator No. 1 (Koch-Light) or a scintillant of toluene $(70 \%, v / v)$ containing $30 \%(v / v)$ Triton-X-100 and $0.5 \%$ (w/v) PPO. The radioactivity of the contents of vials was measured in a Packard Tricarb liquid scintillation spectrometer (model 3385). Velocities of accumulation were determined from the linear segments of plots of the time-course of accumulation for up to $3 \mathrm{~min} 15 \mathrm{~s}$. Velocity values quoted are means of at least three separate measurements on different batches of organisms.

The fate of accumulated amino acids was followed by examining hot-water extracts of organisms that had 
accumulated L-glutamic acid or L-histidine for ${ }^{1+} \mathrm{C}$-containing compounds. Organisms were removed from suspensions as already described, and filters with organisms were immersed in $2 \mathrm{ml}$ water at $100^{\circ} \mathrm{C}$ for $10 \mathrm{~min}$. The suspension was then filtered through a membrane filter $(0.45 \mu \mathrm{m}$ pore size, $25 \mathrm{~mm}$ diam; Millipore), freeze dried overnight and resuspended in $50 \mu \mathrm{l}$ water. Ninhydrin-positive compounds in the filtrate were separated by paper chromatography using the solvent system: butan-1-ol/water/glacial acetic acid $(12: 5: 3$, by vol.). Chromatograms were dried, sprayed with ninhydrin $(0.1 \%, w / v$, in butan-1-ol saturated with water) and the location of spots marked. They were then exposed to photographic plates (Kodak Industrex $C$ ) for at least 4 weeks. Chromatographic examination of extracts of organisms that had accumulated either of the amino acids for up to 5 min revealed only one radioactive spot, with an $R_{F}$ value identical with that of the amino acid used.

Computer-aided statistical analysis. Data on accumulation of each amino acid were examined for their ability to fit each of three models describing, respectively, a single accumulation system, with and without a diffusion component, and a double accumulation system without diffusion. The equations describing each of the models were:

$$
\begin{gathered}
r=\frac{V_{\text {max }}[S]}{K_{\mathrm{T}_{1}}+[S]} \\
r=\frac{V_{\text {max }}[S]}{K_{\mathrm{T}_{1}}+[S]}+D[S] \\
r=\frac{V_{\text {max }}[S]}{K_{\mathrm{T}_{1}}+[S]}+\frac{V_{\text {max: }}[S]}{K_{\mathrm{T}_{2}}+[S]}
\end{gathered}
$$

in which $\boldsymbol{r}$ is the transport velocity, $\boldsymbol{K}_{\mathrm{T}_{1}}$ and $\boldsymbol{K}_{\mathrm{t}}$, are half-saturation constants for each of the two independent accumulation systems, $V_{\text {max }_{1}}$ and $V_{\text {max }}$ are the maximum velocities for the two systems. [S] is the substrate concentration, and $D$ the diffusion constant. Using standard non-linear regression analysis, computer programs were used to assess the ability of experimental data to fit each of the three equations (Cleland. 1979: Mannervik. 1982). A weighting was applied. proportional to the reciprocal of the square of the standard deviation, thereby placing greatest emphasis on data points which were most accurately described. Alternative weightings were examined, but these did not alter the soundness of fit of data for any amino acid. When a set of data was fitted to any two of the models, the fits were considered to be significantly different when the probability of identity value $(P)$ was less than 0.05. $P(1,2)$ indicates, for example, the probability that model 2 is not a better fit than model 1 . Kinetic constants for amino-acid accumulation generated by this statistical analysis were considered to be different if values differed by more than the sum of their standard errors.

Lipid analysis. Cultures destined to be a source of organisms for lipid analysis were supplemented 15 min before harvesting with cycloheximide $\left.(10 \mu \mathrm{g} \mathrm{m})^{-1}\right)$ and chloramphenicol $\left.(10 \mu \mathrm{g} \mathrm{m})^{-1}\right)$. After filtration. as already described, organisms were washed twice on the filter with PIPES buffer (pH 4.5), and lipid was extracted by a modification of the procedures of Folch $e t$ al. (1957) and Watson \& Rose (1980). Freshly washed organisms (500 $\mathrm{mg}$ dry wt) were mixed with methanol $(10 \mathrm{ml})$ and the suspension was shaken in a Braun homogenizer (B. Braun, Melsungen. West Germany) for two periods of $30 \mathrm{~s}$ at speed 2 (4000 r.p.m.) after addition of $35 \mathrm{~g}$ of glass beads (Glasperlen, B. Braun; 0.45-0.50 mm diam). Chloroform was then added to the suspension to give the ratio $2: I(v / v)$ chloroform/methanol, and the suspension was stirred on a flatbed stirrer for $2 \mathrm{~h}$ at room temperature $\left(20-24^{\circ} \mathrm{C}\right)$. The suspension was then filtered through Whatman No. 44 filter paper, and the extraction procedure was repeated on the residue. The combined extracts were washed with 0.25 vol. $0.88 \%(w / v) \mathrm{KCl}$, and the mixture was separated by centrifugation. The lower phase was removed, taken to dryness on a rotary evaporator, and the residue was immediately dissolved in a minimum of chloroform/methanol $(2: 1, v / v)$. Samples were stored under nitrogen gas at $-20^{\circ} \mathrm{C}$. Phospholipids in the extracts were separated from other lipid classes by thin-layer chromatography on plates of silica gel $\mathbf{H}(0.5 \mathrm{~mm}$ thick $)$ using a solvent system of hexane/diethyl ether/acetic acid $(70: 30: 2$, by vol.). Lipid bands were located by exposing the plates to iodine vapour, and were marked with pins. The phospholipid band was identified by reference to simultaneously run standards of phosphatidylcholine or phosphatidylethanolamine. The iodine was allowed to sublime at room temperature, the phospholipid band scraped off the plates, and fatty-acid methyl esters were prepared by refluxing the silica gel with methanol $(2 \mathrm{ml})$ containing $14 \%(w / v) B F_{3}$ for $10 \mathrm{~min}$. After cooling. an equal volume of water was added, and the methyl esters were extracted into chloroform. Fatty-acid methyl esters were analysed by GLC on a column ( $1.5 \mathrm{~m}) \mathrm{of} 15 \%$ EGSS-Y supported on 100 to 120 mesh Gas-Chrom $\mathrm{P}$ at $180^{\circ} \mathrm{C}$. The injection port was at $220^{\circ} \mathrm{C}$, and the carrier

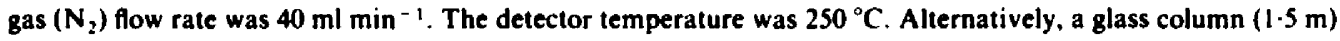
containing $10 \% \mathrm{~S} 2330$ on $100-120$ mesh $\mathrm{Chromosorb}$ W-A W was used at $170{ }^{\circ} \mathrm{C}$ with the carrier gas $\left(\mathrm{N}_{2}\right)$ flow rate $30 \mathrm{ml} \mathrm{min}^{-1}$, and the detector at $270^{\circ} \mathrm{C}$. Percentage fatty-acyl compositions were calculated using a Pye Unicam CDPI computing integrator. 
Chemicals. All chemicals used were Analar grade or of the highest purity available commercially. Ergosterol, palmitoleic acid ( $\Delta^{9}$-cis-hexadecenoic acid), oleic acid ( $\Delta^{9}$-cis-octadecenoic acid), linoleic acid $\left(\Delta^{9},{ }^{12}\right.$ cis, cisoctadecadienoic acid) and PIPES were purchased from Sigma. Cycloheximide and chloramphenicol were obtained from BDH. Radioactively labelled amino acids came from Amersham International. GLC columns were purchased from Applied Science Laboratories, State College, Pa., USA

\section{RESULTS}

\section{Fatty-acyl composition of organisms grown anaerobically in the presence of different} unsaturated fatty acids

Organisms grew anaerobically at the same rate (generation time $1.7 \mathrm{~h}$ ) in media containing palmitoleic, oleic or linoleic acid. Moreover, the lag phase of growth had the same duration in each of the three media. Phospholipids from organisms grown in the presence of palmitoleic or oleic acids were enriched to approximately $69 \%$ of the total with fatty-acyl residues that were chromatographically identical with the fatty acid included in the medium (Table 1). Growth in the presence of linoleic acid brought about a somewhat smaller enrichment ( $51 \%$ of the total) of cellular phospholipids with $\mathrm{C}_{18: 2}$ residues (Table 1).

\section{Statistical analysis of data}

A very good fit to model I was obtained with data for accumulation of L-serine and L-threonine by organisms enriched in oleyl or linoleyl residues (Fig. 1). These data did not fit models 2 and 3. Woolf-Hofstee plots (Hofstee, 1959) for accumulation of both amino acids, by organisms enriched in either fatty-acyl residue, exhibited an abrupt change in curvature at low concentrations of solute (Fig. 1). Values for $K_{\mathrm{T}}$ and $\boldsymbol{V}_{\max }$ for accumulation of L-serine were calculated using data points over the concentration range $25 \mu \mathrm{M}-1 \mathrm{mM}$, assuming a linear relationship between these points. Kinetic constants for accumulation of L-threonine were similarly calculated using data points in the concentration range 50-500 $\mu \mathrm{M}$. Kinetic constants for accumulation of L-serine did not differ for organisms enriched in oleyl as compared with linoleyl residues. There were, however, significant differences in $K_{\mathrm{T}}$ and $\boldsymbol{V}_{\max }$ values for accumulation of L-threonine by organisms enriched in oleyl as compared with linoleyl residues. An excellent fit to model 2 was obtained with data for accumulation of L-histidine (Table 2). The other two models gave less significant fits with these data. $V_{\max }$ values were virtually identical for accumulation of this amino acid by organisms enriched in palmitoleyl, oleyl or linoleyl residues. However, $\boldsymbol{K}_{\mathrm{T}}$ values differed for organisms enriched in palmitoleyl or linoleyl residues as compared with those enriched in oleyl residues. Values for the diffusion constant were different in organisms enriched in each of these three residues. A significant fit to model 2 was also obtained with data for accumulation of $L$-aspartic acid $\left[K_{\mathrm{T}} 62.39 \pm 14.99 \mu \mathrm{M}, V_{\max } 74.21 \pm\right.$ $\left.10.88 \mathrm{pmol}(\mathrm{mg} \text { dry wt) })^{-1} \mathrm{~s}^{-1}, D 0.17 \pm 0.01 \mu \mathrm{l}\left(\mathrm{mg}_{\mathrm{g}} \text { dry wt}\right)^{-1} \mathrm{~s}^{-1}\right]$, although there were no significant differences between the kinetic constants for organisms enriched in oleyl or linoleyl residues. Significant fits to model 3 were obtained with data for accumulation of L-glutamic acid [high-affinity system: $K_{\mathrm{T}} 19.94 \pm 1.86 \mu \mathrm{M}, V_{\max } 30.50 \pm 1.91 \mathrm{pmol}(\mathrm{mg} \text { dry wt) })^{-1} \mathrm{~s}^{-1}$; lowaffinity system: $K_{\mathrm{T}} 3337 \pm 252 \mu \mathrm{M}, V_{\max } 1054 \pm 44 \mathrm{pmol}(\mathrm{mg} \text { dry wt) })^{-1} \mathrm{~s}^{-1}$ ] and L-methionine [high affinity system: $K_{\mathrm{T}} 36.19 \pm 7.98 \mu \mathrm{M}, V_{\max } 85.11 \pm 17.99 \mathrm{pmol}(\mathrm{mg} \text { dry wt) })^{-1} \mathrm{~s}^{-1}$; lowaffinity system: $\left.K_{\mathrm{T}} 1829 \pm 510 \mu \mathrm{M}, V_{\max } 883 \pm 106 \mathrm{pmol}(\mathrm{mg} \text { dry wt) })^{-1} \mathrm{~s}^{-1}\right]$. Substitution of oleyl by linoleyl residues did not change kinetic constants for accumulation of these amino acids. Data for accumulation of L-leucine, L-isoleucine and L-valine did not significantly fit any of the three models. Woolf-Hofstee plots for accumulation of L-leucine by organisms enriched in oleyl residues were superimposable on those for accumulation of this amino acid by organisms enriched in linoleyl residues, as were plots for accumulation of L-isoleucine. However, WoolfHofstee plots for accumulation of L-valine differed in shape for organisms enriched in oleyl as compared with linoleyl residues. 

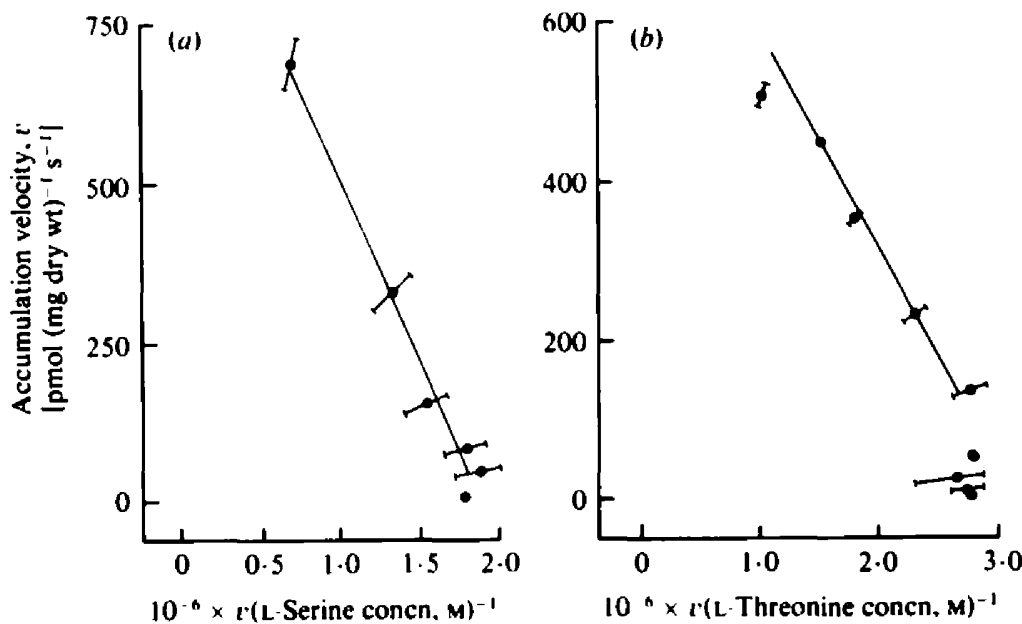

Fig. I. Woolf-Hofstee plots for accumulation of L-serine (a) and L-threonine (b) by Saccharomyces cerevisiae Y 185 with phospholipids enriched in linoleyl residues. Each point represents the average of four determinations. Kinetic constants were calculated using the equation for model I (see text) and data points in the concentration ranges indicated in the text. For organisms enriched in linoleyl residues, kinetic constants for accumulation of $L$-serine were: $K_{\mathrm{T}} 0.58 \pm 0.03 \mathrm{mM} ; V_{\max } 1085.6 \pm$ $28.9 \mathrm{pmol}(\mathrm{mg} \mathrm{dry} w t)^{-1} \mathrm{~s}^{-1}$. Corresponding values for accumulation of $L$-threonine were: $K_{\mathrm{T}} 0 \cdot 21 \pm$ $0.02 \mathrm{~mm}$ and $V_{\max } 732.9 \pm 35.7 \mathrm{pmol}\left(\mathrm{mg}\right.$ dry $\mathrm{wt}^{-1} \mathrm{~s}^{-1}$. Kinetic constants for accumulation by organisms enriched in oleyl residues (plots not shown) were, for $L$-serine, $K_{\mathrm{T}} 0.56 \pm 0.07 \mathrm{mM}, V_{\max }$ $1064.6 \pm 83.0 \mathrm{pmol}(\mathrm{mg} \text { dry } w \mathrm{t})^{-1} \mathrm{~s}^{-1}$; and for L-threonine, $K_{T} 0.28 \pm 0.03 \mathrm{mM}, V_{\max } 890.9 \pm$ $56.6 \mathrm{pmol}(\mathrm{mg} \text { dry } w t)^{-1} \mathrm{~s}^{-1}$.

Table 1. Fatty-acyl composition of phospholipids from S. cerevisiae Y185 grown anaerobically in media containing different unsaturated fatty acids

Fatty acid supplement

Palmitoleic acid Oleic acid Linoleic acid

Content $(\%$ of total) of residues of :

\begin{tabular}{cccccccc}
\hline$C_{12: 0}$ & $C_{14: 0}$ & $C_{14: 1}$ & $C_{16: 0}$ & $C_{16: 1}$ & $C_{18: 0}$ & $C_{18: 1}$ & $C_{18: 2}$ \\
0.5 & 2.2 & 0.7 & 24.1 & 69.4 & 3.2 & $T R$ & - \\
$T R$ & 8.4 & - & 21.7 & $T R$ & 1.8 & 68.6 & $T R$ \\
$T R$ & 5.8 & - & 38.2 & $T R$ & 4.9 & $T R$ & 51.1
\end{tabular}

- Values quoted are the average of two independent analyses; TR, trace; - the residue was not detected.

Table 2. Kinetic constants calculated by computer analysis of data for accumulation of L-histidine by $S$. cerevisiae Y185 with phospholipids enriched in palmitoleyl, oleyl or linoleyl residues

Details of the computer-aided statistical analysis used are given in the text.

\section{Constant}

$\boldsymbol{K}_{\mathrm{T}}(\mu \mathrm{M})$

$V_{\max }\left[\mathrm{pmol}(\mathrm{mg} \text { dry } w t)^{-1} \mathrm{~s}^{-1}\right]$

Difiusion constant $\left[\mu \mid(m g \text { dry } w t)^{-1} s^{-1}\right]$

P(1,2)
Values for organisms with phospholipids enriched in:

\begin{tabular}{|c|c|c|}
\hline $\begin{array}{l}\text { Palmitoleyl } \\
\text { residues }\end{array}$ & $\begin{array}{l}\text { Oleyl } \\
\text { residues }\end{array}$ & $\begin{array}{l}\text { Linoleyl } \\
\text { residues }\end{array}$ \\
\hline
\end{tabular}

$\begin{array}{ccc}2.92 \pm 0.45 & 3.71 \pm 0.20 & 2.55 \pm 0.44 \\ 22.79 \pm 1.64 & 23.71 \pm 0.67 & 24.68 \pm 2.03 \\ 0.070 \pm 0.007 & 0.140 \pm 0.004 & 0.110 \pm 0.010 \\ 0.0024 & 0.000055 & 0.0023\end{array}$




\section{DISCUSSION}

Previous reports from this laboratory have shown that the kinetics of accumulation of L-arginine, L-asparagine and L-lysine may be influenced by the nature of the fatty-acyl enrichment in the plasma membrane of $S$. cerevisiae (Keenan \& Rose, 1979; Keenan et al., 1982). L-Histidine, L-threonine and L-valine can now be added to this list, these being the only three of the nine amino acids examined in the present study found to have kinetics that are so influenced. The effect of membrane fatty-acyl composition on kinetics of L-histidine accumulation differs from the effects already reported for accumulation of L-arginine, L-asparagine and L-lysine. Firstly, changes in fatty-acyl composition affected the $K_{\mathrm{T}}$ value for accumulation of L-histidine, the $V_{\max }$ value remaining virtually constant. Previous reports of effects of fatty-acyl unsaturation on amino-acid accumulation by $S$. cerevisiae (Keenan \& Rose, 1979; Keenan et al., 1982) described changes in both $K_{T}$ and $V_{\max }$ values. The second difference concerns the apparent involvement of diffusion in accumulation of L-histidine by $S$. cerevisiae, a phenomenon not previously reported to be involved in amino-acid accumulation in this yeast. The possibility that this amino acid can diffuse across the yeast plasma membrane is interesting since, under physiological conditions, it exists as a cation. The only previous indication that L-histidine may diffuse across the plasma membrane in $S$. cerevisiae came in a brief comment by Crabeel \& Grenson (1970) to an ability to grow L-histidine permease-less mutants only in the presence of high concentrations of the amino acid. It was somewhat surprising to observe a lower diffusion constant for L-histidine for organisms with plasma membranes more fluid as a result of enrichment with linoleyl or palmitoleyl residues as compared with oleyl residues. The opposite effect might have been expected on the grounds that fluidity would accelerate diffusion; however, virtually nothing is known of the effect of membrane lipid composition on diffusion of charged molecules. Apart from the very good fit of our data to model 2, and the poor fit to model 3, we discount the operation of two accumulation systems for L-histidine for the following additional reasons. Firstly, Woolf-Hofstee plots of the data show no inclination to intersect with the velocity axis which would be expected if a second low-affinity accumulation system were present. Secondly, manipulation of the equation for model 3 indicates that if a second saturable system is present but is unsaturated, then the $K_{\tau}$ value for such a system would be in the region of $50 \mathrm{~mm}$ or higher.

The different $V_{\max }$ values for accumulation of L-threonine by organisms enriched in oleyl as compared with linoleyl residues also indicates that increased fluidity is not necessarily associated with increased $V_{\max }$ values. Accumulation of L-serine and L-threonine had in common that Woolf-Hofstee plots showed an abrupt change in curvature at low concentrations of the amino acid. Similar abrupt changes in curvature of Woolf-Hofstee plots have been reported with uptake by yeasts of cations (Borst-Pauwels et al., 197I ; Borst-Pauwels, 1973), Lasparagine (Gregory et al., 1982) and sugars (Janda et al., 1976). A possible explanation for these changes is that, in addition to the L-serine- and L-threonine-binding sites involved in transport, there exist one or possibly more additional sites for each amino acid occupation of which is necessary to activate the site involved in amino-acid transport. At low concentrations of amino acid, binding to these additional sites might lower the concentration of amino acid to a value at which the rate of its accumulation was affected. At high concentrations of L-serine and Lthreonine, all binding sites would be saturated, so that the effect would not be manifested.

At concentrations greater than those at which these effects operate, accumulation of L-serine and $L$-threonine could be described by a single system. Woolf-Hofstee plots for accumulation of L-threonine were slightly convex at these higher concentrations, a finding also consistent with a multisite model (Borst-Pauwels, 1981). Preston et al. (1974) and Thomson (1979) showed that convex Woolf-Hofstee plots can be explained by the presence of unstirred layers at the outer surface of the plasma membrane. While this concept has not been extensively explored with micro-organisms, it is clearly possible that the presence of the thick hydrophilic wall on the outside of the plasma membrane could lead to formation of unstirred layers that do not equilibrate with the suspending liquid. Support for a role for unstirred layers came from calculations of the permeability $\left(V_{\max } K_{\mathrm{T}}{ }^{-1}\right)$ for low concentrations of solute. For organisms enriched in oleyl or linoleyl residues, permeability values (Fig. 1) are greater for accumulation of 
L-threonine than for L-serine, which correlates with the departure from linearity at low concentrations of solute. Presumably, other amino acids do not show this effect because organisms possess low-velocity high-affinity accumulation systems which are capable of accumulating amino acids present at low concentration. Interestingly, Theuvenet \& Bindels (1980) reported virtually identical convex Woolf-Hofstee plots for accumulation of rubidium ions for spheroplasts and intact organisms of a strain of $S$. cerevisiae suggesting that the wall provides little in the way of a diffusional impediment.

The inability to fit data for accumulation of L-leucine, L-isoleucine and L-valine to any of the models suggests that accumulation of each of these amino acids probably involves one or more processes other than a transport system that can be described by Michaelis-Menten kinetics and diffusion. However, lack of fit to any model makes further comment on the difference in shapes of Woolf-Hofstee plots for accumulation of L-valine somewhat hazardous.

This research was carried out with financial assistance from the SERC under research grant no. GR/B/25728, for which we express our gratitude. Acknowledgement is also made to SERC and the Brewing Research Foundation. Nutfield. Surrey, England, for the Co-operative Award in Science and Engineering awarded to J. C

J. R. Woodward of the Biotechnology Unit, University of Leeds kindly provided the strain of $S$. cererisiae used in this study.

\section{REFERENCES}

Alterthum, F. \& Rose, A. H. (1973). Osmotic lysis of sphaeroplasts from Saccharomyces cerevisiae grown anaerobically in media containing different unsaturated fatty acids. Journal of General Microbiology 77, 371-382.

Andreasen, A. A. \& Stjer, T. J. B. (1953). Anaerobic nutrition of Saccharomyces cererisiae. I. Ergosterol requirement for growth in a defined medium. Journal of Cellular and Comparatite Physiology $\mathbf{4 1}$, 23-36.

Andreasen, A. A. \& Stier, T. J. B. (1954). Anaerobic nutrition of Saccharomyces cerevisiae. It. Unsaturated fatly acid requirement for growth in a defined medium. Journal of Cellular and Comparatice Physiology 43, 271-281.

Borst-Pauwels, G. W. F. H. (1973). Two-site single carrier transport kinetics. Journal of Theoretical Biology 40, 19-31.

Borst-PaUWels, G. W. F. H. (1981). Ion transport in yeast. Biochimica et biophysica acta 650, 88-127.

Borst-Pauwels, G. W. F. H., Wolters, G. H. J. \& HeNDRicks, J. J. G. (1971). The interaction of 2,4dinitrophenol with anaerobic $\mathbf{R b}^{*}$ transport across the yeast cell membrane. Biochimica et biophysicu acta 225, 269-276.

Bussey, H. \& UmbarGer, H. E. (1970a). Biosynthesis of the branched-chain amino acids in yeast: a leucine-binding component and regulation of leucine uptake. Journal of Bacteriology 103, 277-285.

Bussey, H. \& UMBarger, H. E. (1970b). Biosynthesis of the branched chain amino acids in yeast: a trifluoroleucine-resistant mutant with altered regulation of leucine uptake. Journal of Bacteriology 103 , 286-294.

Cleland, W. A. (1979). Statistical analysis of enzyme kinetic data. Methods in Enzymology 63, 103-138.

Cockburn, M., Earnshaw, P. \& Eddy, A. A. (1975). The stoicheiometry of the absorption of protons with phosphate and glutamate by yeasts of the genus Srccharomyces. Biochemical Journal 146, 705.712.
Crabeel, M. \& Grenson, M. (1970). Regulation of histidine uptake by specific feedback inhibition of two histidine permeases in Saccharomyce's cerevisiae. European Journal of Biochemistry 14, 197-204.

Darte, C. \& Grenson, M. (1975). Evidence for three glutamic acid transporting systems with specialized physiological functions in Saccharomy'ces cerevisiae. Biochemical and Biophysical Research Communications 67, 1028-1033.

EDDY, A. A. (1982). Mechanisms of solute transport in selected eukaryotic micro-organisms. Adrances in Microbial Physiology 23, 1 - 78.

Folch, J., Lees, M. \& Sloane Stanley, G. H. (1957). A simple method for the isolation and purification of total lipids from animal tissues. Journal of Biological Chemistry 226, 497-509.

Gits, J. J. \& Grenson, M. (1967). Multiplicity of the amino acid permeases in Saccharomyces ceretisiae. III. Evidence for a specific methionine-transporting system. Biochimica et biophy'sica acta 135, 507-516.

Gregory, M. E., Keenan, M. H. J. \& Rose, A. H. (1982). Accumulation of L-asparagine by Saccharomices cerevisiae X-2180. Journal of General Microbiology 128, 25572562.

Grenson, M. \& Hou, C. (1972). Ammonia inhibition of the general amino acid permease and its suppression in NADPH-specific glutamate dehydrogenaseless mutants of Saccharomyces cererisiae. Biochemical and Biophysical Research Communications 48. 749 -756.

Grenson, M., Crabeel. M., Wiame, J. M. \& Béchet. J. (1968). Inhibition of protein synthesis and simulation of permease turnover in yeast. Biochemical and Biophysical Research Communications 30. 414-419.

Grenson, M., Hou, C. \& Crabeel. M. (1970). Multiplicity of the amino acid permeases in Saccharomyces cerevisiae. IV. Evidence for a general amino acid permease. Journal of Bacteriology 103, 770.777.

HOFsteE, B. H. J. (1959). Non-inverted versus inverted 
plots in enzyme kinetics. Nature, London 184. 1296 1298.

JANDA, S., KotYk, A. \& Tauchovi, R. (1976). Monosaccharide transport systems in the yeast Rhodotorula glutinis. Archites of Microbiology 111, ISI-154.

Joiris, C. R. \& Grenson, M. (1969). Spécificité el régulation d'une perméase des acides aminés dicarboxyliques chez Saccharomyces cererisiae. Archices internationales de phy siologie et de biochimie 77 . 154-156.

Keenan, M. H. J. \& Rose, A. H. (1979). Plasmamembrane lipid unsaturation can affect the kinetics of solute accumulation by Saccharomyces cererisiae. FEMS Microbiology Letters 6. 133-137.

Keenan, M. H. J., Rose, A. H. \& Silverman, B. W. (1982). Effect of plasma-membrane phospholipid unsaturation on solute transport into Saccharomyces cerevisiae. Journal of General Microbiology' 128, 2547 2556.

LIGHT, R. J., LenNaRz, W. J. \& Bloch, K. (1962). The metabolism of hydroxysteatic acids in yeast. Journal of Biological Chemistry 237, 1793-1800.

MANNervik, B. (1982). Regression analysis, experimental error, and statistical criteria in the design and analysis of experiments for discrimination between rival kinetic models. Methods in Enzymology 87, 370 390.

MAw, G. A. (1963). The uptake of some sulphurcontaining amino acids by brewer's yeast. Journal of General Microbiology 31, 247-259.

Preston, R. L., Schaeffer. J. F. \& Curran, P. F. (1974). Structure affinity relationships for the neutral amino acid transpont system in rabbit ileum. Journal of General Physiology 64, 443-467.

Proudlock, J. W., WheEldoN, L. W., Jollow, D. J.
\& LinNane, J. W. (1968). Role of sterols in Saccharomyces cererisiae. Biochimica et biophysica acra 152, 434-447.

RAmos, E. H., DE Bongloanni, L. C. \& Stoppani, A. O. M. (1975). Energy requirements for the uptake of $L$ leucine by Saccharamyces ceretisiae. Biochimica et biophysica acta 394, 470-481.

Ramos. E. H. de Bongloann, L. C., Cuesta Casado, M. C. \& Stoppanl, A. O. M. (1977). Some properties of $\mathrm{L}^{-14} \mathrm{C}$ leucine transport in Saccharomyces ellipsoideus. Biochimica et biophysica acta 467, 220-237.

RAMOS. E. H. DE BONGIOANNI, L. C. \& STOPPANI. A. O. M. (1980). Kinetics of $L^{-1+C}$ leucine transport in Saccharomyces cerevisiae. Biochimica et biophysica acta 599, 214-231.

R yTKA, J. (1975). Positive selection of general amino acid permease mulants in Saccharomjces cererisiae. Journal of Bacteriology 121. 562-570.

Theuvenet. A. P. R. \& Bindels. R. J. M. (1980). An investigation into the feasibility of using yeast protoplasts to study the ion transport properties of the plasma membrane. Biochimica et biophysica acta 599, 587-595.

Thomson, A. B. R. (1979). Limitations of the EadieHofstee plot to estimate kinetic parameters of intestinal transport in the presence of an unstirred water layer. Journal of Membrane Biology 47, 39-57.

WAtson, K. \& Rose, A. H. (1980). Fatty-acyl composition of the lipids of Saccharomyces cererisiae grown aerobically or anaerobically in media containing different fatty acids. Journal of General Microbiology 117, 225-233.

WICKERHAM, L. J. (1951). Taxonomy of yeasts. I. Techniques of classification. United States Department of Agriculture Technical Bulletin, No. 1029. Washington, DC: US Department of Agriculture. 